\title{
PROPOSTA DE ROTEIRO DE AUDITORIA DA QUALIDADE DE SOFTWARES DE SISTEMAS DE INFORMAÇÕES CONTÁBEIS
}

\section{A PROPOSAL FOR A ROUTINE TO AUDIT THE QUALITY OF ACCOUNTANCY INFORMATION SYSTEM SOFTWARE}

\author{
Elizabeth Krummenacher Marçal \\ Mestre em Ciências Contábeis pelo \\ Programa de Pós-Graduação em Ciências Contábeis - PPGCC \\ da Universidade Regional de Blumenau - FURB \\ Rua Antônio da Veiga, 140 - Victor Konder - Blumenau /SC - Brasil \\ CEP 89012-900 - e-mail: beth.sci@terra.com.br - Tel. (47) 33210565 \\ Ilse Maria Beuren \\ Doutora em Controladoria e Contabilidade pela FEA/USP \\ Professora do Programa de Pós-Graduação em Ciências Contábeis \\ da Universidade Regional de Blumenau - PPGCC/FURB \\ Rua Antônio da Veiga, 140 - Victor Konder - Blumenau /SC - Brasil \\ CEP 89012-900 - e-mail: ilse@furb.br - Tel. (47) 33210565
}

\begin{abstract}
RESUMO
O presente estudo especifica uma proposta de roteiro de auditoria da qualidade de softwares de sistemas de informações contábeis, considerando as características e subcaracterísticas específicas da qualidade de softwares. Para tal realizou-se um estudo exploratório, com abordagem qualitativa. Como procedimentos de pesquisa utilizaram-se a observação e a técnica de entrevista. Uma entrevista estruturada foi realizada com um analista de sistemas de informações contábeis, cujas atribuições vão desde a análise do software junto aos desenvolvedores até o atendimento ao usuário final. Os resultados da pesquisa evidenciam um roteiro de auditoria da qualidade de softwares de sistemas de informações contábeis com as etapas e as respectivas fases que destacam os níveis de qualidade das características e subcaracterísticas específicas e qualidade final do software. A proposição de um roteiro de auditoria mostra-se relevante, tanto na perspectiva de quem desenvolve o software quanto de seus usuários.
\end{abstract}

Palavras-chave: Roteiro de auditoria da qualidade. Qualidade de softwares. Software de sistemas de informações contábeis.

\section{ABSTRACT}

This study proposes a routine for auditing the quality of accountancy information system software, taking into consideration the characteristics and sub-characteristics of the quality of the software. The procedures used in the study were observation and interviewing techniques. To achieve this, an exploratory study using a qualitative approach was carried out. A structured interview was conducted with an accountancy systems analyst, whose observations go from analysis of the software with its developers to attending the end user. The results of this research outline a routine whereby the quality of accountancy software can be audited with the steps and respective phases which highlight the levels of quality of the specific 
characteristics and sub-characteristics and the final quality of the software. The proposal of a system of auditing the quality of accountancy software is shown to be relevant, as much as from the perspective of those who develop the software as to those who use it.

Keywords: routine for auditing the quality; software quality; accountancy information system software.

\section{INTRODUÇÃO}

Com o surgimento da informática, o esforço inicial das organizações era o seu uso exclusivamente na automatização de operações repetitivas, que demandavam longo tempo e um número elevado de pessoas para sua execução. Com o passar dos tempos, começaram a ser desenvolvidos sistemas de informações computadorizados, para auxiliar no monitoramento e no controle de processos e operações das empresas.

Aos poucos foi ocorrendo uma evolução significativa no desenvolvimento de softwares, inclusive com a criação de sistemas de informações de suporte a todas as etapas do processo de gestão empresarial e para os diversos níveis hierárquicos. Novas tecnologias foram surgindo, paralelamente com o desenvolvimento dos meios de comunicação, implicando mudanças substanciais, até na forma das pessoas e organizações se relacionarem.

A evolução tecnológica tem se refletido nas organizações como um todo, proporcionando formas de relacionamentos modernos, como a comunicação entre softwares diferentes, transferência de dados de uma localização física para outra, permitindo transações com clientes e fornecedores via redes digitais. Estas formas de comunicação, aliadas à informática, viabilizam a transmissão de dados, voz, imagens ou sons, através de canais de comunicação, como fibras óticas, microondas terrestres, satélites e outras transmissões sem fio, o que resulta em velocidade e agilidade na comunicação dos dados.

Como conseqüência, esse processo traz consigo a preocupação dos gestores com a qualidade das informações geradas. E é nesta perspectiva que a auditoria exerce papel importante, particularmente a auditoria de sistemas, que foca, de forma primordial, a capacidade do software em gerar informações adequadas e seguras. $\mathrm{O}$ trabalho da auditoria de sistemas consiste em assegurar aos desenvolvedores e usuários dos softwares que os mesmos estão de acordo com as reais necessidades da organização.

Deve assegurar que possuam as características essenciais de um sistema informatizado, como funcionalidade, confiabilidade, usabilidade, eficiência, manutenibilidade e portabilidade. Estas características, aplicadas no software e prontamente identificadas pelo 
auditor, contribuem para a qualidade das informações geradas. Este acompanhamento é relevante, pois visa o controle permanente para seu adequado funcionamento. A auditoria de sistemas de informações desempenha esta função.

Embora se reconheça sua relevância, é uma atividade recente, e sua evolução é significativa, devido ao fato das organizações não mais sobreviverem sem as informações geradas com o suporte da tecnologia. Assim, o objetivo do trabalho é especificar uma proposta de roteiro de auditoria da qualidade de softwares de sistemas de informações contábeis, que considere as características e subcaracterísticas específicas da qualidade de softwares.

Os sistemas de informações contábeis configuram como uma categoria específica de softwares, que têm como finalidade capturar, armazenar e processar dados, transformando-os e produzindo informações contábeis. Com a crescente evolução das tecnologias de informação e as constantes mudanças em legislações tributárias, estes softwares sofrem freqüentes alterações, o que justifica a preocupação com a auditoria da qualidade de softwares de sistemas de informações contábeis.

\section{AVALIAÇÃO DA QUALIDADE DE SOFTWARES}

Os cuidados durante o desenvolvimento do software implicam diretamente na sua qualidade final. Buscando a qualidade, o foco deve estar em todas as etapas do processo de desenvolvimento, com o intuito de assegurar a consonância entre processos, antecipando-se a erros. Bartié (2002, p.16) define qualidade de software como "um processo sistemático que focaliza todas as etapas e artefatos produzidos com o objetivo de garantir a conformidade de processos e produtos, prevenindo e eliminando defeitos".

Shiller (1992) entende que software de qualidade é aquele que cumpre seus objetivos, é gerenciável, é possível de manutenção, tem longa duração e é de fácil aprendizado e operacionalização. Fontes (1991, p.29) expõe que "a qualidade de um sistema informatizado deve ser medida pela exatidão dos dados processados, dos cálculos efetuados, dos produtos oferecidos e da tempestividade de suas rotinas".

A qualidade possui características capazes de determinar quão satisfatoriamente as necessidades dos usuários do softwere são atendidas. A NBR ISO/IEC 14598-1, de agosto de 2001, no item 4.21, conceitua qualidade de softwere como a "totalidade de características que lhe confere a capacidade de satisfazer as necessidades explícitas e implícitas”. 
As necessidades implícitas, para Fernandes (1995), são as condições e os objetivos propostos por aqueles que produzem o software. Os fatores implícitos da qualidade são relativos ao desenvolvimento do software e são perceptíveis por pessoas envolvidas neste processo. Por sua vez, as necessidades explícitas são aquelas individuais de cada cliente. Os fatores explícitos também podem ser percebidos pelos desenvolvedores, mas são principalmente considerados pelos usuários, pois são qualidades definidas por eles.

Além dos aspectos da qualidade que são definidos pelos desenvolvedores e usuários dos softwares, há também normas específicas a respeito do assunto, que devem ser respeitadas para conferir a qualidade desejada em um software.

\subsection{Normas da qualidade de softwares}

As normas da série ISO 9000 tratam da gestão e garantia da qualidade. Elas estabelecem as diretrizes que norteiam a organização na busca da qualidade, quer seja de bens, serviços ou processos. São emitidas pela International Organization for Standarization (ISO), grupo internacional de normalização, localizado em Genebra Suíça, que não possui ligações com órgãos governamentais

No que concerne às normas de qualidade de softwares, este órgão já tem emitido várias normas específicas. No Brasil, as certificações são feitas através da ABNT (2004). Para acompanhar a qualidade estabelece procedimentos, parâmetros e medidas capazes de investigar se um produto está dentro de limites aceitáveis. O Quadro 1 apresenta as principais normas nacionais e internacionais de qualidade de softwares.

\begin{tabular}{|l|l|l|}
\hline \multicolumn{1}{|c|}{ NORMA } & ANO & \multicolumn{1}{c|}{ ASSUNTO QUE DISPÕE A NORMA } \\
\hline NBR ISO/IEC 9126 & 1991 & Qualidade de produto de softwares \\
\hline NBR ISO/IEC 9126-1 & 2003 & Engenharia de software - Qualidade de produto. Parte 1: Modelo de qualidade \\
\hline NBR ISO/IEC 14598 & 2001 & Avaliação de produtos de softwares \\
\hline NBR ISO/IEC 14598-1 & 2001 & Avaliação de produto de software - Visão geral \\
\hline NBR ISO/IEC 14598-2 & 2001 & Avaliação de produto de software - Planejamento e gestão \\
\hline NBR ISO/IEC 14598-3 & 2003 & Avaliação de produto de software - Processo para desenvolvedores \\
\hline NBR ISO/IEC 14598-4 & 2003 & Avaliação de produto de software - Processo para adquirentes \\
\hline NBR ISO/IEC 14598-5 & 2001 & Avaliação de produto de software - Processo para avaliadores \\
\hline NBR ISO/IEC 12119 & 1998 & Pacotes de software - Testes e requisitos de qualidade \\
\hline NBR ISO 8402 & 1994 & Gestão da qualidade e garantia da qualidade - terminologia. \\
\hline NBR ISO 9001 & 1994 & $\begin{array}{l}\text { Sistemas de qualidade }- \text { modelo para garantia da qualidade em projeto, } \\
\text { desenvolvimento, instalação e assistência técnica (processo). }\end{array}$ \\
\hline NBR ISO 9003 & 1994 & $\begin{array}{l}\text { Gestão de qualidade e garantia da qualidade. Aplicação da norma ISO 9000 } \\
\text { para o processo de desenvolvimento de software }\end{array}$ \\
\hline NBR ISO 10011-1 & 1993 & Diretrizes para auditoria de sistemas da qualidade - Auditoria \\
\hline NBR ISO 10011-2 & 1993 & $\begin{array}{l}\text { Diretrizes para auditoria de sistemas da qualidade - Critérios para qualificação } \\
\text { de auditores de sistemas da qualidade }\end{array}$ \\
\hline NBR ISO 10011-3 & 1993 & $\begin{array}{l}\text { Diretrizes para auditoria de sistemas da qualidade - Gestão de programas de } \\
\text { auditoria }\end{array}$ \\
\hline
\end{tabular}


ISO/IEC 15504 SPICE 2003 Aprovada em outubro de 2003.

Quadro 1 - Normas nacionais e internacionais de qualidade de softwares

A ISO/IEC 15504 SPICE está sendo desenvolvida desde 1993 pela ISO em conjunto com a comunidade internacional através do projeto SPICE (Software Process Improvement and Capality Determination). Trata especificamente de avaliação de processos de softwares (www.tecsoft.softex.br/not-mes11--17--03.php). Está sendo elaborada em conjunto pela ISO e pela IEC (www.isospice.com), e constitui uma padronização para avaliar o processo do software, estabelecendo uma organização neste processo. A norma ISO/IEC 15504 SPICE consubstancia-se da integração dos padrões já existentes, além da flexibilidade e adaptação às características e necessidades para avaliações de processos de softwares, com vistas em assegurar o mínimo de qualidade.

\subsection{Características da qualidade de softwares de sistemas de informações contábeis}

As características da qualidade de softwares são as principais métricas avaliadas, que possibilitam determinar o seu nível de qualidade. O Subcomitê de Software da ABNT (www.pr.gov.br/abntsoftware/), através do glossário de termos e expressões, explicita que as características "são um conjunto de atributos de software, através do qual sua qualidade é descrita e avaliada. Uma característica de qualidade de software pode ser detalhada em múltiplos níveis de subcaracterísticas".

O atributo é uma qualidade que se pode medir. Segundo o Subcomitê de Software da ABNT (www.pr.gov.br/abntsoftware/), o atributo é "uma propriedade mensurável, física ou abstrata, de uma entidade".

A NBR 13596, de abril de 1996, estabelece as características que delineiam a qualidade de um software. Por sua vez, a NBR ISO/IEC 9126-1, publicada em junho de 2003, na introdução, explica que a NBR 13596 foi substituída pela NBR ISO/IEC 9126 (Qualidade do produto de software) e pela NBR ISO/IEC 14598 (Avaliação do produto de software).

Como a NBR ISO/IEC 9126 é uma revisão da NBR 13596 e mantém as mesmas características de qualidade de software, utilizou-se a NBR 13596, de abril de 1996, para descrever as seis características que delineiam a qualidade de software, refinadas com suas subcaracterísticas.

\subsubsection{Funcionalidade}


Na NBR 13596, publicada em abril de 1996, no item 4.1 consta que a funcionalidade compreende um "conjunto de atributos que evidenciam a existência de um conjunto de funções e suas propriedades específicas. As funções são as que satisfazem as necessidades explícitas ou implícitas”.

As subcaracterísticas são importantes para a definição da qualidade de um software. A NBR 13596, de abril de 1996, no item A.2.1., traz as subcaracterísticas da funcionalidade e seus atributos:

a) adequação - são atributos do software que poderão influenciar na presença de funções para executar tarefas específicas e objetivas de uso;

b) acurácia - são os atributos do software que detectam a presença de resultados corretos e em conformidade com a necessidade;

c) interoperabilidade - são atributos do software que têm influências na habilidade de interação com um ou mais sistemas específicos;

d) conformidade - influencia na aderência à convenções ou regulamentos legais e prescrições similares;

e) segurança - estes atributos influenciam na habilidade de controlar acessos não intencionados, resistir a ataques intencionados para acesso à informações confidenciais.

A característica funcionalidade tem como foco fundamental a satisfação do cliente, abrangendo atributos que são determinados pelas subcaracterísticas adequação, acurácia, interoperabilidade, conformidade e segurança.

\subsubsection{Confiabilidade}

A característica confiabilidade, de acordo com a NBR 13596, de abril de 1996, no item 4.2., é o "conjunto de atributos que evidenciam a capacidade do software de manter seu nível de desempenho sob condições estabelecidas durante um período de tempo estabelecido". Por sua vez, o item A.2.2., traz as subcaracterísticas da característica confiabilidade, juntamente com seus atributos:

a) maturidade - é o atributo do software que evidencia a freqüência de falhas por defeitos no software;

b) tolerância à falhas - é o atributo do software que evidencia sua capacidade em manter um nível de desempenho especificado nos casos de falhas no software ou de violação nas interfaces especificadas; 
c) recuperabilidade - são atributos do software que evidenciam sua capacidade de estabelecer seu nível de desempenho e recuperar os dados diretamente afetados, em caso de falhas, e no tempo e esforço necessários para tal.

Como em softwares não há desgastes, as limitações da confiabilidade estão relacionadas aos defeitos de projetos ou de implementações, que podem ocasionar falhas.

\subsubsection{Usabilidade}

A NBR 13596, de abril de 1996, no item 4.3., define a característica usabilidade como o "conjunto de atributos que evidenciam o esforço necessário para se poder utilizar o software, bem como o julgamento individual desse uso, por um conjunto explícito ou implícito de usuários". No item A.2.3 estão explicitadas as subcaracterísticas relativas à usabilidade, bem como seus atributos:

a) inteligibilidade - atributo do software que evidencia o esforço do usuário para reconhecer o conceito lógico e sua aplicabilidade;

b) apreensibilidade - atributos que evidenciam o esforço do usuário para aprender sua aplicação, por exemplo, controle de operação, entradas, saídas;

c) operacionalidade - atributos do software que evidenciam o esforço do usuário para realizarsua operação e controle da sua operação.

Os atributos da usabilidade avaliam o grau de dificuldade que o usuário têm ao operar e aprender a usar o software, efetuando uma análise acerca deste uso.

\subsubsection{Eficiência}

Na NBR 13596, publicada em abril de 1996, no item 4.4., a característica eficiência é conceituada como um "conjunto de atributos que evidenciam o relacionamento entre o nível de desempenho do software e a quantidade de recursos usados, sob condições estabelecidas". No item A.2.4. é elencada a subcaracterística comportamento e os respectivos atributos para a eficiência, como segue:

a) comportamento com relação ao tempo - compreende atributos do software que evidenciam seu tempo de resposta, tempo de processamento e velocidade na execução de suas funções;

b) comportamento com relação aos recursos - são atributos do software que evidenciam a quantidade de recursos usados e a duração de seu uso na execução de suas funções. 
No que concerne à característica eficiência, os atributos que podem ser analisados são itens como papel de impressora, discos de armazenamento de dados, manutenção e suporte.

\subsubsection{Manutenibilidade}

Segundo a NBR 13596, de abril de 1996, no item 4.5., a característica manutenibilidade é definida como o "conjunto de atributos que evidenciam o esforço necessário para fazer modificações especificadas no software". No item A.2.5. estão definidas as subcaracterísticas da característica manutenibilidade, bem como seus atributos:

a) analisabilidade - atributos do software que evidenciam o esforço necessário para diagnosticar deficiências ou causas de falhas, ou para identificar partes a serem modificadas;

b) modificabilidade - atributos do software que mostram o esforço necessário para modificá-lo, remover seus defeitos ou adapta-lo a mudanças ambientais;

c) estabilidade - atributos do software que evidenciam o risco de efeitos inesperados, ocasionados por modificações; e

d) testabilidade - atributos do software que demonstram o esforço necessário para validar o software modificado.

$\mathrm{Na}$ característica manutenibilidade, as suas subcaracterísticas mostram atributos que podem incluir correções, melhorias ou adaptações nos softwares.

\subsubsection{Portabilidade}

A característica portabilidade, conforme a NBR 13596, de abril de 1996, item 4.6., é o "conjunto de atributos que evidenciam a capacidade do software de ser transferido de um ambiente para outro". O item A.2.6. aponta as subcaracterísticas e atributos da portabilidade:

a) adaptabilidade - atributos do software que demonstram sua capacidade de ser adaptado a ambientes diferentes, sem a necessidade de aplicação de outras ações ou meios além daqueles fornecidos para essa finalidade pelo software considerado;

b) instalação - atributos do software que mostram o esforço necessário para sua instalação em um ambiente especificado;

c) capacidade de substituição - atributos do software que mostram sua capacidade e esforço necessário para substituir um outro software, no ambiente estabelecido para este outro software. 
A característica portabilidade, quando se refere à mudança de ambiente, pode ser mudança de ambiente organizacional, hardware ou software. Seus atributos demonstram a habilidade do software em adaptar-se a novos ambientes, legislação, sua conformidade com padrões, e facilitadores para substituição.

\section{METODOLOGIA DA PESQUISA}

Considerando o objetivo estabelecido, o presente estudo consiste de uma pesquisa exploratória. Martins (2002, p.23-34) cita que a pesquisa exploratória é indicada quando "se tem pouco conhecimento do assunto. É uma abordagem adotada para a busca de maiores informações sobre determinado assunto de estudo. Possui um planejamento flexível para possibilitar a consideração dos mais diversos aspectos de um problema".

No desenvolvimento do estudo exploratório foi utilizada abordagem qualitativa. No que concerne à abordagem qualitativa, Richardson $(1999$, p.80) descreve que "os estudos que empregam uma metodologia qualitativa podem descrever a complexidade de determinado problema, analisar a interação de certas variáveis, compreender e classificar processos dinâmicos vividos por grupos sociais".

O critério utilizado na escolha da empresa desenvolvedora de softwares de sistemas de informações contábeis foi o de acessibilidade. A empresa selecionada desenvolve softwares de escrituração contábil, escrituração fiscal, folha de pagamento, controle de ativo imobilizado, livro de apuração do lucro real, administração de condomínios e gerenciador de escritório.

De acordo com a natureza deste trabalho, o software selecionado para testar a proposta foi o de escrituração contábil. Os elementos analisados no software de sistema de informações contábeis selecionado foram as características da qualidade de softwares evidenciados na fundamentação teórica, com ênfase na funcionalidade, confiabilidade, conformidade, usabilidade, eficiência, manutenibilidade e portabilidade.

A pessoa entrevistada para validar a proposta foi um analista de sistemas de informações contábeis, cujas atribuições vão desde a análise do software juntamente com os desenvolvedores, até o atendimento ao usuário final. Portanto, possui profundo conhecimento acerca deste software, tanto no aspecto funcional quanto operacional.

$\mathrm{O}$ instrumento de pesquisa adotado foi um roteiro de entrevista estruturado. A entrevista estrutura foi elaborada com base no instrumento de pesquisa de Poffo (1995) e 
Storch (2000). No entanto, foram necessárias adaptações quanto ao conteúdo das perguntas, inserção de novas questões e maior detalhamento em algumas situações.

As questões foram separadas em características e subcaracterísticas, direcionadas aos diversos atributos destas, procurando concentrar o maior número possível de questões alusivas àquele atributo. As perguntas disponibilizaram duas opções de resposta: sim ou não. Para fins de análise receberam pontuações diferentes, dependendo da característica analisada.

\section{PROPOSTA DE ROTEIRO DE AUDITORIA DA QUALIDADE DE SOFTWARES}

A proposta de roteiro de auditoria da qualidade de softwares de sistemas de informações contábeis foi elaborada com base nas normas especificadas e sintetizadas no Quadro 2.

\begin{tabular}{|c|c|}
\hline ASSUNTO & NORMAS E DISPOSIÇÃO \\
\hline Auditoria de sistemas & $\begin{array}{l}\text { NBR ISO 10011-1 Diretrizes para a auditoria de sistemas da qualidade. Parte } 1 \\
\text { - Auditoria } \\
\text { NBR ISO 10011-2 Diretrizes para a auditoria de sistemas da qualidade. Parte } 2 \\
\text { - Critérios para qualificação de auditores de sistema da qualidade } \\
\text { NBR ISO 10011-3 Diretrizes para a auditoria de sistemas da qualidade. Parte } 3 \\
\text { - Gestão de programas de auditoria } \\
\text { NIA } 300 \text { - Planejamento. Pronunciamentos Internacionais de Práticas de } \\
\text { Auditoria }\end{array}$ \\
\hline Qualidade de softwares & $\begin{array}{l}\text { NBR ISO/IEC 9126-1 Engenharia de software - Qualidade de produto. Parte 1: } \\
\text { Modelo de qualidade } \\
\text { NBR } 13596 \text { Tecnologia de informação - Avaliação de produtos de software - } \\
\text { Características de qualidade e diretrizes para o seu uso. } \\
\text { NBR ISO } 8402 \text { Gestão da qualidade e garantia da qualidade - Terminologia. }\end{array}$ \\
\hline $\begin{array}{l}\text { Processo de avaliação de } \\
\text { software }\end{array}$ & $\begin{array}{l}\text { NBR ISO/IEC 14598-1 Tecnologia de informação - Avaliação de produto de } \\
\text { software. Parte } 1 \text { - Visão geral } \\
\text { NBR ISO/IEC 14598-2 Engenharia de software - Avaliação de produto. Parte } 2 \\
\text { - Planejamento e gestão } \\
\text { NBR ISO/IEC 14598-3 Engenharia de software - Avaliação de produto. Parte } \\
3 \text { - Processo para desenvolvedores } \\
\text { NBR ISO/IEC 14598-4 Engenharia de software - Avaliação de produto. Parte } 4 \\
\text { - Processo para adquirentes } \\
\text { NBR ISO/IEC 14598-5 Engenharia de software - Avaliação de produto de } \\
\text { software. Parte } 5 \text { - Processo para avaliadores } \\
\text { NBR ISO/IEC } 12119 \text { Tecnologia de informação - Pacotes de software - testes } \\
\text { e requisitos de qualidade. }\end{array}$ \\
\hline
\end{tabular}

Quadro 2 - Normas usadas na proposta de roteiro de auditoria da qualidade de softwares

$\mathrm{O}$ roteiro de auditoria da qualidade de softwares proposto fundamenta-se nas especificações das normas acima, particularmente de normas de auditoria de sistemas da qualidade, de normas de avaliação da qualidade de softwares e de normas do processo de avaliação de softwares. O estudo deste conjunto de normas proporcionou um entendimento mais profundo sobre o tema abordado. 
A NBR ISO/IEC 14598-1, publicada em agosto de 2001, no item 6, esclarece que, "para avaliar a qualidade do software, primeiro se estabelecem os requisitos da avaliação, então se especifica, projeta e executa a avaliação". Também apresenta as etapas e as fases que compõem o processo de avaliação da qualidade de software. Nesta perspectiva foi elaborada a proposta de roteiro de auditoria da qualidade de softwares de sistemas de informações contábeis, cuja configuração está evidenciada na Figura 1.

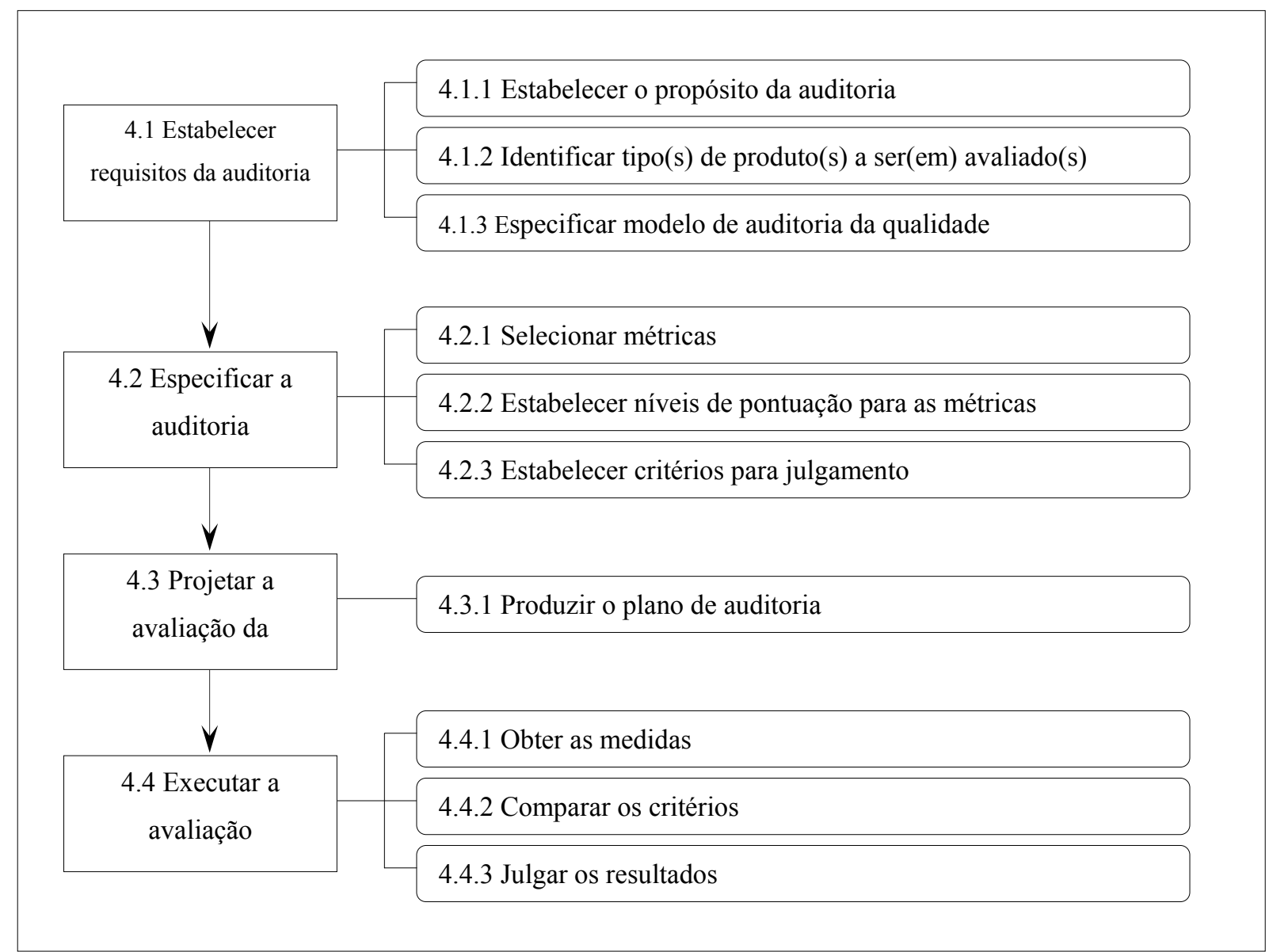

Figura 1 - Etapas e fases do roteiro de auditoria da qualidade de softwares Fonte: adaptada da NBR ISO/IEC 14598-1 (2001).

Cada uma das etapas propostas tem funções específicas e, nesta direção, as mesmas se desdobram em fases, com vistas na operacionalização da auditoria da qualidade de softwares.

\subsection{Estabelecer os requisitos da auditoria}


A auditoria da qualidade de um software requer, como primeira etapa, o estabelecimento dos requisitos da auditoria da qualidade do software. O estabelecimento dos requisitos é fundamental para efetuar a auditoria, pois constituem a base para o entendimento de como este processo de auditoria da qualidade será aplicado.

Esta primeira etapa da proposta de roteiro de auditoria da qualidade de softwares é importante para direcionar corretamente os trabalhos do auditor da qualidade de softwares. Com base na NBR ISO/IEC 14598-1, de agosto de 2001, estabelecer os requisitos da auditoria implica nas seguintes fases: estabelecer o propósito da auditoria, identificar o(s) produto(s) a ser(em) avaliado(s) e especificar o modelo de auditoria da qualidade.

\subsubsection{Estabelecer o propósito da auditoria}

O ponto de partida da auditoria da qualidade de um software ocorre quando há solicitação de uma auditoria. Quando uma auditoria é solicitada, normalmente o requisitante descreve os requisitos que ele deseja que sejam auditados, os quais são analisados pelo auditor. Geralmente, solicitante e auditor entram em acordo quanto à especificação da auditoria como um todo.

Os solicitantes de auditoria da qualidade de software são potencialmente: desenvolvedores, fornecedores, adquirentes e usuários de softwares. Os desenvolvedores de softwares, muitas vezes, estão diretamente envolvidos na auditoria, mesmo que não sejam os solicitantes da auditoria. No caso de avaliação da qualidade de softwares, os resultados podem contribuir para corrigirem falhas, principalmente se o software que está sendo avaliado encontra-se em fase de desenvolvimento.

$\mathrm{O}$ auditor deve garantir ao solicitante que a auditoria da qualidade seja rigorosa o suficiente para fornecer um alto nível de confiabilidade no resultado obtido com a avaliação da qualidade. Portanto, auditor e solicitante devem estar de acordo quanto à extensão e a forma de auditoria, bem como quanto ao real propósito da auditoria.

Para a NBR ISO/IEC 14598-1, de agosto de 2001, o propósito da avaliação no estágio do desenvolvimento pode ser para prevenir e estimar a qualidade do produto final, colher informações sobre o produto em desenvolvimento, para inspecionar e administrar o processo, ou confirmar o término do estágio do desenvolvimento, para iniciar um novo estágio. Assim, o desenvolvedor do software avalia-o antes de colocá-lo à venda, a fim de assegurar a sua qualidade. 
No estágio da aquisição, de acordo com a NBR ISO/IEC 14598-1, de agosto de 2001, a intenção da avaliação pode ser para decidir sobre a aceitação do software, comparar e selecionar um determinado software, entre outros. É possível também analisar pontos positivos e negativos com relação ao software e decidir quando substituir ou aperfeiçoar o mesmo.

Portanto, o propósito da avaliação, tanto do desenvolvedor quanto do adquirente, é ponderar a qualidade do software e analisar se todas as características e subcaracterísticas que determinam a qualidade foram aplicadas, de forma a assegurar que o software funcione adequadamente.

\subsubsection{Identificar tipo(s) de produto(s) a ser(em) avaliado(s)}

A submissão de um software à auditoria da qualidade, para avaliação, deve ocorrer preferencialmente durante o processo de desenvolvimento. Se a auditoria for feita no estágio do desenvolvimento do software, a possibilidade do produto satisfazer aos quesitos considerados no processo de avaliação aumenta substancialmente, assim como minimiza o risco de falhas graves, o que pode acarretar custos extras e inesperados.

No entanto, um software pode ser submetido à auditoria em qualquer momento, bem como em qualquer um dos processos de seu ciclo de vida, como no desenvolvimento, na aquisição, no fornecimento, na operacionalização ou mesmo na manutenção do software.

Se quem deseja auditar o software é o desenvolvedor do produto, ele poderá avaliá-lo tanto na fase de desenvolvimento, no intuito de prevenir e estimar a qualidade, quanto na fase final do produto, antes de colocá-lo efetivamente no mercado. Se quem deseja auditar é o usuário ou adquirente do software, a avaliação será feita no produto final, fornecendo ao auditor e à organização um feedback, com relação ao atendimento às suas necessidades.

\subsubsection{Especificar o modelo de auditoria da qualidade}

A especificação do modelo de auditoria da qualidade implica mostrar os procedimentos a serem usados pelo auditor para realizar as medições que foram solicitadas na especificação da avaliação. $\mathrm{O}$ auditor produz um modelo de qualidade, contendo todos os requisitos determinados entre o solicitante e o auditor.

Este modelo de auditoria da qualidade pode ser determinado pelo auditor na forma de questionário, elaborado com base nos requisitos desejados pelo solicitante da auditoria da 
qualidade. Ao especificar o modelo de qualidade, é preciso especificar quando o questionário será realizado e quem deverá responder as questões.

Deve haver a preocupação com quem responderá o questionário, para que seja um profissional que conheça profundamente o software em análise. Alguns dos profissionais que estão aptos a responder ao questionário são os programadores e os analistas de sistemas.

Com relação à freqüência com que deve ser realizada a avaliação, ela está relacionada à necessidade do solicitante. Por exemplo, se o solicitante for o desenvolvedor, poderá estar solicitando a auditoria da qualidade a cada nova versão que estiver sendo lançada, checando se todas as características relevantes continuam a desempenhar suas funções de forma adequada, sem prejuízo nenhum à qualidade do software. Se o requisitante for o adquirente, a avaliação poderá estar sendo solicitada apenas para escolher o software, ou então, a qualquer tempo que deseje verificar a qualidade do software.

A fase de especificação do modelo de auditoria da qualidade completa a primeira etapa da proposta de roteiro de auditoria da qualidade de softwares, que é estabelecer os requisitos da auditoria. A etapa dará direcionamento ao auditor na condução de seu trabalho.

\subsection{Especificar a auditoria}

A especificação da auditoria consiste na etapa em que devem ser elencadas as quantificações para as características e subcaracterísticas da qualidade de software. As quantificações podem ser obtidas através do estabelecimento de critérios de mensuração, determinando pesos aos requisitos que foram definidos na fase de especificação do modelo, por meio dos quais será possível a avaliação da qualidade do software.

Em conformidade com a NBR ISO/IEC 14598-1, de agosto de 2001, o modelo de auditoria da qualidade deve selecionar as características da qualidade que sejam relevantes. No seu item 7.3 consta que "os modelos de qualidade para avaliação de software geralmente representam a totalidade dos atributos de qualidade de software classificados em uma estrutura de árvore hierárquica de características e subcaracterísticas”.

A etapa de especificação da auditoria, do roteiro de auditoria da qualidade de softwares de sistemas de informações contábeis, está voltada à forma de avaliar a qualidade de softwares. Esta segunda etapa da proposta contempla três fases: selecionar métricas, estabelecer níveis de pontuação para as métricas e estabelecer critérios para julgamento.

\subsubsection{Selecionar métricas}


O resultado da avaliação da qualidade de softwares está relacionado às métricas selecionadas, que aumentam a sua confiabilidade. $\mathrm{O}$ estabelecimento das métricas que podem ser utilizadas para a avaliação da qualidade de softwares está baseada na NBR ISO/IEC 91261, de junho de 2003, que define as seis características que descrevem a qualidade de softwares e fornecem base de refinamento para a avaliação da qualidade. A NBR 13596, de abril de 1996, somente fornece as seis principais características, não trazendo métodos para medição, pontuação ou julgamento.

No entanto, esta norma traz uma sugestão de estabelecimento de subcaracterísticas para as características, mas esclarece que as subcaracterísticas podem não ser estas. Dependendo do software que estiver sendo avaliado e da relevância da avaliação, as subcaracterísticas poderão ser diferentes, ou poderão ter pesos diferentes, o que alterará os resultados da avaliação da característica. Somente é possível avaliar um software, ao se dispor de algum método quantitativo ou quantificável, que possa ser correlacionado às características e subcaracterísticas da qualidade.

No Quadro 3 apontam-se as características funcionalidade, confiabilidade, usabilidade, eficiência, manutenibilidade e portabilidade. Tais características consubstanciam a qualidade de softwares, sendo que suas respectivas subcaracterísticas, complementadas por perguntas chaves, podem auxiliar nos procedimentos de auditoria da qualidade de softwares.

\begin{tabular}{|c|c|c|}
\hline CARACTERÍSTICA & SUBCARACTERÍSTICAS & PERGUNTAS CHAVES \\
\hline $\begin{array}{l}\text { Funcionalidade } \\
\text { Satisfaz as } \\
\text { necessidades? }\end{array}$ & $\begin{array}{c}\text { Adequação } \\
\text { Acurácia } \\
\text { Interoperabilidade } \\
\text { Conformidade } \\
\text { Segurança }\end{array}$ & $\begin{array}{l}\text { Faz o que é apropriado? } \\
\text { Executa o que foi proposto de forma correta? } \\
\text { Há interabilidade com os sistemas especificados? } \\
\text { Normas, leis, etc, são respeitadas? } \\
\text { Checa acesso de pessoas não autorizadas às } \\
\text { informações? }\end{array}$ \\
\hline $\begin{array}{l}\text { Confiabilidade } \\
\text { É imune à falhas? }\end{array}$ & $\begin{array}{l}\text { Maturidade } \\
\text { Tolerância à falhas } \\
\text { Recuperabilidade }\end{array}$ & $\begin{array}{l}\text { As falhas são freqüentes? } \\
\text { Qual a reação do sistema, quando da ocorrência de } \\
\text { falhas? } \\
\text { Há a possibilidade de recuperação de dados em caso de } \\
\text { falhas? }\end{array}$ \\
\hline $\begin{array}{l}\text { Usabilidade } \\
\text { É fácil de usar? }\end{array}$ & $\begin{array}{l}\text { Inteligibilidade } \\
\text { Apreensibilidade } \\
\text { Operacionalidade }\end{array}$ & $\begin{array}{l}\text { É fácil entender o conceito e a aplicação? } \\
\text { Há dificuldades em aprender a usá-lo? } \\
\text { Há dificuldades de operacionalização e controles? }\end{array}$ \\
\hline $\begin{array}{l}\text { Eficiência } \\
\text { É rápido e "enxuto"? }\end{array}$ & $\begin{array}{l}\text { Comportamento quanto } \\
\text { ao tempo } \\
\text { Comportamento quanto } \\
\text { aos recursos } \\
\end{array}$ & $\begin{array}{l}\text { O tempo de resposta e a velocidade de execução são } \\
\text { aceitáveis? } \\
\text { Usa muitos recursos? São usados durante muito tempo? }\end{array}$ \\
\hline Manutenibilidade & Analisabilidade & É fácil identificar uma falha, quando ela ocorre? \\
\hline
\end{tabular}




\begin{tabular}{|c|c|l|}
\hline É fácil de modificar? & $\begin{array}{l}\text { Modificabilidade } \\
\text { Estabilidade }\end{array}$ & $\begin{array}{l}\text { É fácil modifica-lo e adaptá-lo á novas realidades? } \\
\text { Quando se fazem alterações, há riscos eminentes de } \\
\text { erros, falhas? } \\
\text { Após alterações, são feitos testes? Estes testes são } \\
\text { fáceis de fazer? }\end{array}$ \\
\hline $\begin{array}{c}\text { Portabilidade } \\
\text { É fácil de usar em } \\
\text { outro ambiente? }\end{array}$ & $\begin{array}{l}\text { Adaptabilidade } \\
\text { Instalação }\end{array}$ & $\begin{array}{l}\text { É fácil adaptá-lo a outros ambientes? } \\
\text { É fácil instalá-lo em outros ambientes? } \\
\text { Capacidade de substituição substituir outro sistema, possui facilitadores para } \\
\text { isso? }\end{array}$ \\
\hline
\end{tabular}

Quadro 3 - Características e subcaracterísticas da qualidade de softwares

Fonte: elaborado com base na NBR 13596, de abril de 1996, NBR ISO/IEC 12119, de outubro de 1998, NBR ISO/IEC 9126-1, de junho de 2003, Inthurn (2001, p.37-38) e Paladini Sobrinho (2002, p.12).

A fase de seleção das métricas é uma fase importante e complexa no processo de auditoria da qualidade, especificamente quando seu propósito é avaliar a qualidade de um software. Funcionalidade, confiabilidade, usabilidade, eficiência, manutenibilidade e portabilidade são as principais características estabelecidas na proposta, cada uma com suas respectivas subcaracterísticas perguntas chaves.

\subsubsection{Estabelecer níveis de pontuação para as métricas}

Depois de estabelecidas as métricas, o próximo passo é atribuir níveis de pontuação às mesmas, para fazer a avaliação da qualidade do software. Assim, busca-se representar a qualidade de forma numérica, de maneira que possa ser quantificável.

Segundo Antonioni e Rosa (1995), inexistem métricas gerais mundialmente aceitas para avaliar a qualidade de softwares. Inclusive alguns especialistas consideram que as métricas existentes não são suficientemente maduras. Assim, cabe ao auditor estabelecer métodos que possam diminuir a subjetividade. Uma das formas é determinar que a avaliação seja feita por vários auditores. Outra possibilidade é por meio de processos organizados, de modo a obter medidas quantificáveis.

Uma outra alternativa para obter níveis de pontuação para as métricas é estabelecer graus de relevância para as subcaracterísticas, atribuindo-lhes pesos. Ao se estabelecer pesos para as subcaracterísticas, a característica terá seu peso máximo de acordo com a soma das suas subcaracterísticas. Esta alternativa é a que se propõe neste estudo

\subsubsection{Grau de relevância}

As características e subcaracterísticas do software a serem avaliadas possuem grau de relevância diferente para cada empresa, pois, normalmente, é o solicitante (desenvolvedor, adquirente ou usuário) quem define a respectiva pontuação, juntamente com o auditor.

Revista Produção Online, Florianópolis, v.7, n.7,p.86, dez./abr., 2007 
Os métodos de pontuar são definidos para todas as subcaracterísticas selecionadas. O grau ou nível de pontuação pode ser formatado a partir de uma medida qualitativa, através de termos que expressem esta medida, como, relevância: alta, média ou baixa.

No Quadro 4 propõe-se medidas qualitativas para o grau de relevância das subcaracterísticas das características funcionalidade, confiabilidade, usabilidade, eficiência, manutenibilidade e portabilidade.

\begin{tabular}{|c|c|c|c|}
\hline $\begin{array}{c}\text { CARACTERÍSTICAS/ } \\
\text { SUBCARACTERÍSTICAS }\end{array}$ & RELEVÂNCIA & $\begin{array}{c}\text { CARACTERÍSTICAS/ } \\
\text { SUBCARACTERÍSTICAS }\end{array}$ & RELEVÂNCIA \\
\hline FUNCIONALIDADE & & CONFIABILIDADE & \\
\hline Adequação & Alta & Maturidade & Alta \\
\hline Acurácia & Alta & Tolerância à falhas & Alta \\
\hline Interoperabilidade & Alta & Recuperabilidade & Média \\
\hline Conformidade & Média & & \\
\hline Segurança & Alta & & \\
\hline USABILIDADE & & EFICIÊNCIA & \\
\hline Inteligibilidade & Média & Comportamento quanto ao tempo & Alta \\
\hline Apreensibilidade & Média & $\begin{array}{c}\text { Comportamento quanto aos } \\
\text { recursos }\end{array}$ & Média \\
\hline Operacionalidade & Média & & \\
\hline MANUTENIBILIDADE & & PORTABILIDADE & \\
\hline Analisabilidade & Média & Adaptabilidade & Média \\
\hline Modificabilidade & Média & Instalação & Alta \\
\hline Estabilidade & Alta & Capacidade de substituição & Média \\
\hline Testabilidade & Alta & & \\
\hline
\end{tabular}

Quadro 4 - Medidas qualitativas para o grau de relevância das subcaracterísticas

Fonte: elaborado com base na NBR ISO/IEC 14598-1 e Ferreira (2003, p. 60-62).

É necessário também estabelecer medidas quantitativas, atribuindo pesos a esta relevância, determinadas em conjunto pelo solicitante e pelo auditor. Os pesos representam a importância daquela subcaracterística perante a característica. Desta maneira, terão um valor numérico que viabilizará a avaliação.

Complementando a fase de estabelecer níveis de pontuação, o grau de relevância de cada subcaracterística necessita de níveis para classificar a pontuação obtida. Desse modo, estes níveis podem ser considerados em termos percentuais, para facilitar a avaliação da representatividade da relevância. No caso, a qualidade final do software obedece aos seguintes níveis de satisfação: excelente (90,1\% a 100\%); bom (75,1\% a 90\%); satisfatório $(60,1 \%$ a $75,0 \%)$; regular $(50,1 \%$ a $60,0 \%)$ e insatisfatório ( $0 \%$ a $50 \%)$. 
As características, que tem seu grau de relevância estabelecido de acordo com a soma dos pesos de suas características, também são classificadas dentro dos níveis estabelecidos acima.

Os níveis de pontuação não são conhecidos de antemão, pois são particulares em cada caso e em cada organização. Portanto, podem ser necessárias adaptações à situações específicas que o solicitante da auditoria, juntamente com o auditor, ajustam para adequar-se à circunstância.

Quando a opção para estabelecer níveis de pontuação para as métricas for através do grau de relevância, torna-se necessário ainda estabelecer fórmulas para se poder avaliar a qualidade do software.

\subsubsection{Fórmulas para os níveis de qualidade}

Para realizar o cálculo do nível da qualidade do software são necessários alguns elementos, como as métricas, os níveis de pontuação, o grau de relevância e outros dados mais específicos, obtidos a partir de entrevista estruturada, elaborada e aplicada pelo auditor, e que complementam a auditoria da qualidade. No entanto, para a viabilização do cálculo é fundamental o estabelecimento de fórmulas, para calcular os níveis de qualidade do software.

Inicia-se com as fórmulas para calcular o nível de qualidade da subcaracterística, o que possibilitará a avaliação de quais subcaracterísticas encontram-se com desempenho inadequado. Quando o nível de qualidade da subcaracterística é calculado, leva-se em consideração o seu grau de relevância, que influencia no cálculo, pois cada subcaracterística tem grau de relevância diferente.

Uma vez obtido o nível de qualidade da subcaracterística, pode-se estabelecer uma nova fórmula, que permite o cálculo do nível de qualidade daquela característica. $\mathrm{O}$ estabelecimento de uma fórmula é necessário porque cada característica também tem um grau de relevância diferente, em conseqüência de suas subcaracterísticas.

De posse do cálculo do nível de cada característica, nova fórmula pode ser estabelecida, para o cálculo do nível de qualidade do software como um todo, efetuando-se uma média entre os níveis de qualidade obtidos em todas as características e seus pesos.

As fórmulas para calcular o nível de qualidade de subcaracterísticas, características e a para a qualidade final do software, foram adaptadas de Storch (2000, p.42-46).

\section{a) Fórmula para o cálculo do nível de qualidade das subcaracterísticas}


O cálculo do nível de qualidade da subcaracterística pode ser efetuado da seguinte maneira:

$$
\text { NQSC }=\frac{\sum \text { NSC }}{\sum \text { NMSC }}
$$

Onde:

NQSC $=$ Nível de qualidade da subcaracterística

$\sum \mathrm{NSC}=$ Soma das notas das perguntas da subcaracterística

$\sum \mathrm{NMSC}=$ Soma das notas máximas das perguntas da subcaracterística

O denominador da fórmula, $\Sigma$ NMSC, significa dizer que, se há por exemplo, 15 questões sobre esta subcaracterística, e o peso desta característica for 4, então a nota máxima desta subcaracterística será 60. Porém, poderá ocorrer que o peso da subcaracterística seja proporcional às respostas positivas e negativas. E, neste caso, a soma das notas máximas das perguntas, deverá ser o total de respostas positivas multiplicado pelo seu peso proporcional. No mesmo exemplo, se as respostas positivas forem 10, e as negativas forem 5, e o peso para as respostas positivas for 3, e para as negativas for 1, então o $\sum$ NMSC será 30 .

O numerador da fórmula, $\sum$ NSC, soma das notas das perguntas da subcaracterística, cujo peso é 4, se houverem 15 questões, mas destas, 10 forem respondidas sim, e as demais não, a soma das notas das perguntas desta subcaracterística será 35, pois 10 respostas sim multiplicadas pelo peso proporcional 3 é igual a 30, e 5 respostas não multiplicadas pelo peso proporcional 1 é igual a 5, totalizando 35.

A proporcionalidade entre as respostas $\operatorname{sim}$ e não, de acordo com o peso da subcaracterística, se deve ao fato de que as respostas positivas em cada questão têm relevância maior. As questões elaboradas possuem aspecto afirmativo, o que caracteriza que as respostas deveriam ser positivas.

\section{b) Fórmula para o cálculo do nível de qualidade das características}

O cálculo do nível de qualidade das características pode ser realizado através da seguinte fórmula:

$$
\mathrm{NQC}=-\sum\left(\sum \text { NSC }\right)
$$

Revista ProdePnline, Florianópolis, v.7, n.7,p.89, dez./abr., 2007 
Onde :

$\mathrm{NQC}=$ Nível de qualidade da característica

$\sum\left(\sum\right.$ NSC $)=$ Somatória da soma das notas das perguntas de todas as subcaracterísticas vinculadas a esta característica

$\sum\left(\sum\right.$ NMSC $)=$ Somatória da soma das notas máximas das perguntas de todas as subcaracterísticas vinculadas à esta característica

O denominador $\sum$ ( $\sum$ NMSC) é um totalizador das somas de todas as notas máximas das perguntas da subcaracterística. Em outras palavras, são somadas as notas máximas que cada subcaracterística poderia atingir, se todas as questões fossem respondidas como sim. $\mathrm{O}$ numerador $\sum$ ( $\sum$ NSC) representa as respostas sim e não, multiplicadas pelos seus respectivos pesos proporcionais.

\section{c) Fórmula para o cálculo do nível de qualidade final do software}

O cálculo do nível da qualidade final do software pode ser efetuado utilizando-se a fórmula que segue:

$$
\mathrm{NQFS}=-\frac{\sum(\mathrm{NQC} * \mathrm{PC})}{\sum \mathrm{PC}}
$$

Onde:

$\mathrm{NQFS}=$ Nível de qualidade final do software

$\sum(\mathrm{NQC} * \mathrm{PC})=$ Soma do nível de qualidade de todas as características, cada uma multiplicada pelo seu respectivo peso.

$\sum \mathrm{PC}=$ Soma dos pesos das características

O estabelecimento de níveis de pontuação para as métricas viabiliza e facilita a execução da auditoria da qualidade de softwares. Por fim, o estabelecimento de critérios de julgamento complementa o trabalho do auditor, nesta etapa.

\subsubsection{Estabelecer critérios para julgamento}

O julgamento é a etapa final do processo de auditoria da qualidade do software, onde o conjunto de características é sintetizado. O resultado obtido é uma revelação do grau de 
qualidade do software. Os resultados da avaliação são importantes para a tomada de decisão, por exemplo, com base nos resultados obtidos, pode liberar ou não uma versão nova do software, ou mesmo disponibilizar o software para venda.

Porém, para julgar é necessário estabelecer critérios que serão empregados para o julgamento. O método proposto para julgar o resultado da avaliação da qualidade de softwares foi o de adotar a atribuição de medidas conceituais para a avaliação e julgamento final. Os conceitos adotados foram: excelente, bom, satisfatório, regular e insatisfatório.

\subsection{Projetar a avaliação da qualidade}

Projetar a avaliação da qualidade de softwares implica planificar os procedimentos que precisam ser adotados pelo auditor para executar a auditoria da qualidade. O plano de auditoria deve ser detalhado de modo a assegurar que as ações sejam realizadas de forma adequada. Em conformidade com a NBR 14598-1, de agosto de 2001, item 9.1., "o plano de avaliação descreve os métodos de avaliação e o cronograma das ações do avaliador".

A NBR ISO/IEC 14598-5, de agosto de 2001, no item 6.4.2., esclarece que "a atividade para produzir o plano de avaliação é composta de três subatividades: documentar os métodos de avaliação e produzir um plano preliminar, otimizar o plano de avaliação...".

É recomendável que este plano esteja consistente com a NBR ISO/IEC 14598-3, de agosto de 2003, se o solicitante da auditoria for o desenvolvedor. Por outro lado, deve estar em conformidade com a NBR ISO/IEC 14598-4, de junho de 2003, se o solicitante for um adquirente. Para ambos deve considerar a NBR ISO/IEC 14598-5, que trata das diretrizes para avaliadores, como avaliadores de laboratórios de testes, entidades de certificação, adquirentes ou fornecedores.

Esta terceira etapa do roteiro, projetar a avaliação da qualidade, compõe-se apenas de uma fase, produzir o plano de auditoria. O plano da auditoria da qualidade contempla o método de auditoria (estabelece como o propósito da auditoria será atingido) e o cronograma de avaliação, indicando a versão do software em que será realizada a auditoria da qualidade.

\subsection{Executar a avaliação}

A etapa final do roteiro de auditoria da qualidade de softwares de sistemas de informações contábeis gera informações importantes aos solicitantes da auditoria. Os resultados obtidos podem ser analisados individualmente, percebendo-se deficiências em uma determinada subcaracterística, característica ou no software como um todo. 
No entanto, aquele resultado individual da característica ou da subcaracterística pode evidenciar uma deficiência, que talvez não fosse percebida analisando-se o software como um todo. Mesmo que aquela característica ou subcaracterística não tenha atingido um resultado satisfatório, e não comprometa significativamente o nível de qualidade total do software, pode ocorrer uma situação inesperada em decorrência daquela fragilidade.

A execução da auditoria da qualidade é a última etapa do roteiro de auditoria da qualidade de softwares. Esta etapa compõe-se das seguintes fases: obter as medidas, comparar os critérios e julgar os resultados.

\subsubsection{Obter as medidas}

No roteiro de auditoria da qualidade de softwares que se propõe, o método a ser adotado para auxiliar na obtenção das medidas é a aplicação de uma entrevista estruturada, que contenha questões alusivas às características, subcaracterística e seus atributos. As respostas obtidas devem ser sintetizadas, proporcionando os primeiros dados da fase de obtenção das medidas.

A partir destas primeiras medidas, obtêm-se as medidas para todas as subcaracterísticas individualmente, que são os níveis de qualidade para as subcaracterísticas. Na seqüência, as medidas a serem obtidas são os níveis de qualidade para as características, extraídas das subcaracterísticas. E, finalmente, somando o nível das características será possível obter o nível de qualidade final do software.

\subsubsection{Comparar os critérios}

A comparação das medidas com os critérios, na etapa da execução da auditoria, é necessária para verificar se os resultados obtidos estão de acordo com os critérios de avaliação estabelecidos. Esta comparação é feita em todos os níveis, comparando-se primeiramente as medidas de cada subcaracterística com o grau de relevância em percentuais estabelecidos para cada subcaracterística. O próximo passo é realizar a comparação para as medidas das características, também levando em consideração o grau de relevância.

A comparação da qualidade final do software é realizada através do julgamento dos resultados, pois este resultado sintetiza todos os demais, e não há comparação com critérios, mas sim o julgamento desse resultado, quanto ao nível de satisfação.

A fase de comparação dos resultados obtidos com os critérios estabelecidos é significativa, principalmente para agilizar e dar segurança ao julgamento dos resultados. 


\subsubsection{Julgar os resultados}

De posse de todas as medidas, é possível ao auditor realizar o julgamento dos resultados. Julgar significa revelar o nível de satisfação do software, de acordo com os níveis de satisfação articulados na etapa de especificação da avaliação, na fase onde se estabelecem os níveis de pontuação para as métricas.

A comparação da medida de qualidade final do software é realizada comparando o seu resultado com os níveis de classificação estabelecidos: excelente, bom, satisfatório, regular ou ruim.

O desempenho do trabalho do auditor pode ser melhorado se forem observadas as etapas do roteiro de auditoria da qualidade de softwares aqui apresentadas: estabelecer os requisitos da auditoria, especificar a auditoria, projetar a avaliação da qualidade e executar a avaliação. No entanto, as etapas do roteiro de auditoria possuem cada uma, suas próprias fases, que também precisam ser consideradas.

\section{CONSIDERAÇÕES FINAIS}

O presente artigo especificou uma proposta de roteiro de auditoria da qualidade de softwares de sistemas de informações contábeis, considerando as características e subcaracterísticas específicas da qualidade de softwares. Para a elaboração da proposta foi necessário identificar as etapas que compõem o roteiro da auditoria, bem como detalhar cada uma das fases das etapas identificadas. Com o detalhamento das etapas e de suas fases, foi possível compreender a complexidade e a extensão da auditoria da qualidade de softwares, mas que, de posse de um roteiro detalhado, é possível a sua realização. Foram identificadas quatro etapas e suas respectivas fases, que configuram o roteiro de auditoria da qualidade.

A primeira etapa, estabelecer requisitos da auditoria, compreende três fases: estabelecer o propósito da auditoria, identificar o tipo de produto a ser avaliado, especificar o modelo de auditoria da qualidade. A segunda etapa, especificar a auditoria, também é composta de três fases: selecionar as métricas, estabelecer níveis de pontuação para as métricas, estabelecer critérios para julgamento. A terceira etapa, projetar a avaliação da qualidade, consubstancia-se de apenas uma fase: produzir o plano de auditoria. A quarta etapa, executar a avaliação, se constitui de três fases: obter as medidas, comparar os critérios de pontuação, julgar os resultados. 
Pode-se concluir, através deste estudo, que a auditoria, por si só, já possui seus próprios critérios de organização de seus trabalhos, o que facilita a elaboração do roteiro de auditoria da qualidade de softwares. Também já existem métricas pré-definidas para avaliação da qualidade de softwares, que são as características funcionalidade, confiabilidade, usabilidade, eficiência, manutenibilidade e portabilidade.

Assim, é preciso estabelecer os níveis de pontuação para as métricas selecionadas, sendo que o grau de relevância pode ser definido pelo avaliador, juntamente com o solicitante. Adicionalmente, é necessário que o auditor estabeleça os critérios que utilizará para julgar a qualidade, pois a literatura apenas fornece tipos de critérios que podem ser usados para julgar, mas não determina qual critério deve ser utilizado. O auditor estabelecerá o critério que julgar mais relevante.

Por fim, um roteiro de auditoria da qualidade de softwares, no caso específico de sistemas de informações contábeis, é fortemente influenciado pelos avanços tecnológicos que vêm ocorrendo e mudanças na legislação brasileira. Ainda que isto dificulte a elaboração de um modelo padrão de critérios de avaliação, deve-se parametrizar aspectos relevantes para a auditoria da qualidade de softwares desta natureza.

\section{REFERÊNCIAS}

ANTONIONI, José A; ROSA, Newton Braga. Qualidade em software: manual da aplicação da ISO-9000. São Paulo: Makron Books, 1995.

ABNT - ASSOCIAÇÃO BRASILEIRA DE NORMAS TÉCNICAS. ABNT como organismo de certificação. Disponível em: < http://www.abnt.org.br/certif_body.htm>. Acesso em: 22 jul. 2004.

. Glossário de termos e expressões. Disponível em:

<http://www.pr.gov.pr/abntsoftware/ce10101>. Acesso em: 21 abr. 2004.

. NBR 13596: tecnologia de informação - avaliação de produto de software características de qualidade e diretrizes para o seu uso. Rio de Janeiro, abr.1996.

NBR ISO 10011-1: diretrizes para auditoria de sistemas da qualidade. Parte 1: auditoria. Rio de Janeiro, jul. 1993.

. NBR ISO 10011-2: diretrizes para auditoria de sistemas da qualidade. Parte 2: critérios para qualificação de auditores de sistemas da qualidade. Rio de Janeiro, jul. 1993.

. NBR ISO 10011-3: diretrizes para auditoria de sistemas da qualidade. Parte 3: gestão de programas de auditoria. Rio de Janeiro, jul. 1993.

. NBR ISO 9001: sistemas de qualidade - modelo para garantia da qualidade em projeto, desenvolvimento, instalação e assistência técnica (processo). Rio de Janeiro, 1994.

. NBR ISO 9003: gestão da qualidade e garantia da qualidade - terminologia. Aplicação da norma ISO 9000 para o processo de desenvolvimento de software. Rio de Janeiro, 1994. 
. NBR ISO 8402: gestão da qualidade e garantia da qualidade - terminologia. Rio de Janeiro, dez. 1994.

NBR ISO/IEC 12119: tecnologia de informação - pacotes de software - testes e requisitos de qualidade. Rio de Janeiro, out. 1998.

NBR ISO/IEC 14598: tecnologia de informação - avaliação de produto de software. Rio de Janeiro, ago. 2001.

NBR ISO/IEC 14598-1: tecnologia de informação - avaliação de produto de software. Parte 1: visão geral. Rio de Janeiro, ago. 2001.

. NBR ISO/IEC 14598-2: engenharia de software - avaliação de produto. Parte 2: planejamento e gestão. Rio de Janeiro, jun. 2001.

NBR ISO/IEC 14598-3: engenharia de software - avaliação de produto. Parte 3: processo para desenvolvedores. Rio de Janeiro, ago. 2003.

. NBR ISO/IEC 14598-4: engenharia de software - avaliação de produto. Parte 4: processo para adquirentes. Rio de Janeiro, jun. 2003.

. NBR ISO/IEC 14598-5: tecnologia de informação - avaliação de produto de software. Parte 5: processo para avaliadores. Rio de Janeiro, ago. 2001. 1991.

NBR ISO/IEC 9126: engenharia de software - qualidade de produto. Rio de Janeiro,

. NBR ISO/IEC 9126-1: engenharia de software - qualidade de produto. Parte 1: modelo de qualidade. Rio de Janeiro, jun. 2003.

BARTIÉ, Alexandre. Garantia da qualidade de software: as melhores práticas de engenharia de software aplicadas à sua empresa. Rio de Janeiro: Campus, 2002.

FERNANDES, Aguinaldo Aragon. Gerência de software através de métricas: garantindo a qualidade do projeto, processo e produto. São Paulo: Atlas, 1995.

FERREIRA, Fabiano Stimamiglio. Ferramenta para avaliação da qualidade de produtos de software baseado nas normas ISO/IEC 9126 e NBR ISO/IEC 12119. 2003. 103 f.. Trabalho de Conclusão de Curso (Monografia), Curso de Ciências da Computação, Universidade Regional de Blumenau, Blumenau, 2003.

FONTES, Joaquim Rubens. Manual de auditoria de sistemas. Rio de Janeiro: Ciência Moderna, 1991.

INTHURN, Cândida. Qualidade \& teste de software. Florianópolis: Visual Books, 2001.

ISO/IEC 15504. Publicada a Norma ISO 15504 (SPICE) (2003). Disponível em: $<$ http://www.tecsoft.softex.br/not-mes11--17--03.php>. Acesso em: 21 abr. 2004.

MARTINS, Gilberto de Andrade. Manual para elaboração de monografias e dissertações. São Paulo: Atlas, 2002.

PALADINI SOBRINHO, Pietro Carlo. Sistemas de informação para o desenvolvimento e avaliação de sites utilizando a ISO/IEC 9126. 2002. 72 f.. Trabalho de Conclusão do Curso. (Monografia), Curso de Ciências da Computação, Universidade Regional de Blumenau, Blumenau, 2002. Disponível em: <http://www.bc.furb.br/docs/MO/2002/266434_1_1.pdf.>. Acesso em: 04 maio 2004. 
POFFO, Márcio Alberto. Protótipo para a avaliação da qualidade de softwares de contabilidade. 1995. 90 f.. Trabalho de Conclusão de Curso (Monografia), Curso de Ciências da Computação, Universidade Regional de Blumenau, Blumenau, 1995.

RICHARDSON, Roberto Jarry. Pesquisa social: métodos e técnicas. $3^{\mathrm{a}}$. ed. São Paulo: Atlas, 1999.

SHILLER, Lary. Excelência em software. São Paulo: Makron Books, 1992.

STORCH, Mirian Mirdes. Proposta de avaliação da qualidade de produtos de software utilizando a norma ISO/IEC 9126. 2000. 82 f.. Trabalho de Conclusão de Curso (Monografia), Curso de Ciências da Computação, Universidade Regional de Blumenau, Blumenau, 2000.

Artigo Recebido em 02/2006 e aceito para publicação em 04/2007 